\title{
Long-term climatic variations in central Asia and the deVries solar cycle
}

O. Raspopov ${ }^{1}$, V. Dergachev ${ }^{2}$, J. Esper ${ }^{3}$ and T. Kolström ${ }^{4}$

'SPbF IZMIRAN, St. Petersburg, Russia; oleg@OR6074.spb.edu

${ }^{2}$ loffe Physico-Technical Institute, RAS, St. Petersburg, Russia

${ }^{3}$ Swiss Federal Research Institute WSL, Birmensdorf, Switzerland

${ }^{4}$ University of Joensuu, Mekrijärvi Research Station, Finland

It is commonly believed that the $\sim 200$ year deVries cycle is one of the most intense solar cycles (Vasil'ev et al., 1999, Wagner et al., 2001). This is evidenced, for instance, by the occurrence of pronounced solar activity minima (Maunder, Spörer, Wolf) in approx. 200-year intervals during the last millennium. The temporal coincidence between the Maunder (AD 1645-1715), Spörer (AD 1416-1534), and Wolf periods (AD 1280-1350) and the expansion of Alpine glaciers indicates a climatic response to these solar minima (Eddy, 1976). A similar conclusion was recently inferred from an analysis of glacier expansion in Alaska (Wiles et al., 2004).

Here, we aim to reveal the deVries cycle in Central Asia by analyzing treering growth data of Juniperus turkestanica trees from upper timberline sites in the Tien Shan Mountains, and comparing the obtained paleoclimatic record with the 200 -year wavelength solar variations during the last millennium.

To assess long-term climatic fluctuations during the last millennium, treering width variations of Juniperus turkestanica $(\Delta \mathrm{R})$ growing above 2800-2900 $\mathrm{m}$ asl were considered. Trees at these locations in the Tien Shan Mountains can reach ages of 2000 years. Analyses of the climatic signal of Juniper tree-ring width data reveals a clear June-July temperature signal, and no significant influence by precipitation variations (Mukhamedshin and Sarbaev, 1988). Similar conclusions on the dominant influence of summer temperatures on ring-width formation of Juniperus turkestanica were made by Maksimov and Grebenyuk (1972) and Esper et al. (2003). Accordingly, the analysis of long-term Juniper ring-width variations, and a comparison with solar activity variations $(\triangle 14 C$ in our case) allow us to investigate potential relationships between long-term changes in solar activity and summer temperatures in Central Asia.

To reliably separate out $\sim 200$-year fluctuations in $\Delta \mathrm{R}$ for Juniperus turkestanica, we analyzed long-term ring-width records developed for different locations in the Tien Shan Mountains by independent research teams: Maksimov and Grebenyuk (1972), Mukhamedshin and

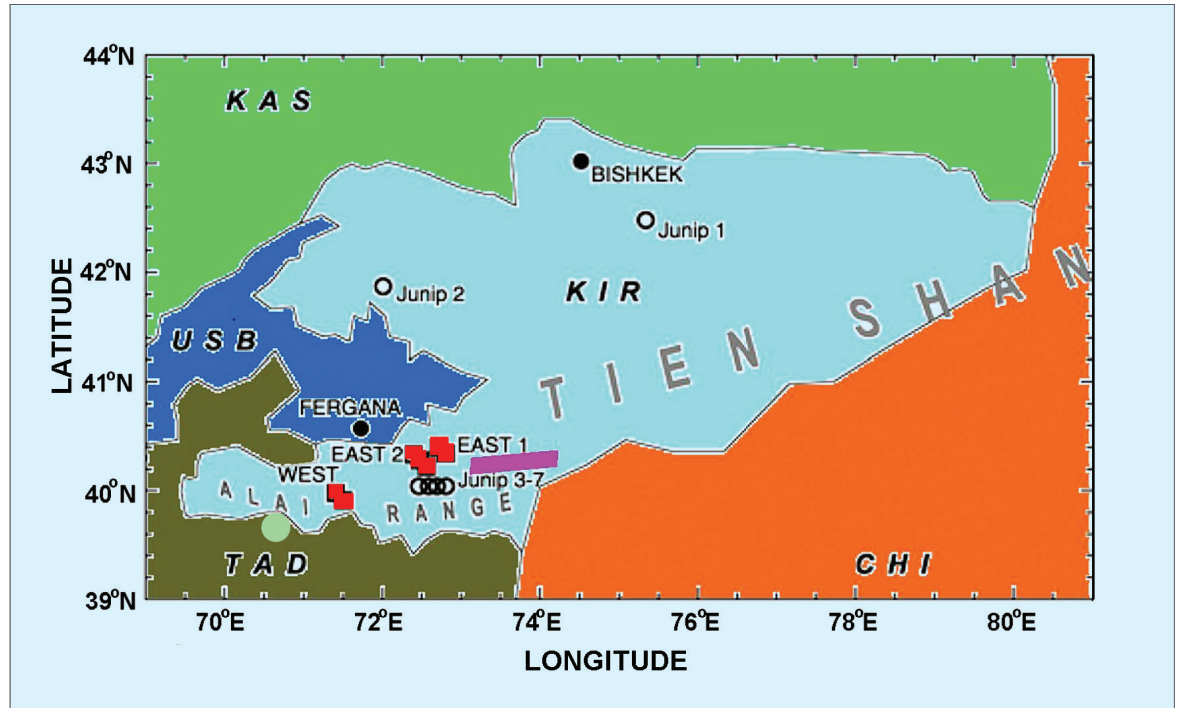

Figure 1: Map showing the locations of the tree-ring sampling sites in the Tien Shan Mountains. The green circle marks the site collected by Maksimov and Grebenyuk (1972), the violet bold line the site collected by Mukhamedshin and Sarbaev (1988), and the red rectangle the site used in Esper et al. (2003b).
Sarbaev (1988), and Esper et al. (2003a). All chronologies reached back to at least 800 years; hence, records are much longer than the periodicity of interest of about 200 years.
-The chronology of Maksimov and Grebenyuk covers the time interval from $A D$ 1170 to 1970 . Samples were collected in Tajikistan on the northern slope of the Zeravshan range, at an altitude of

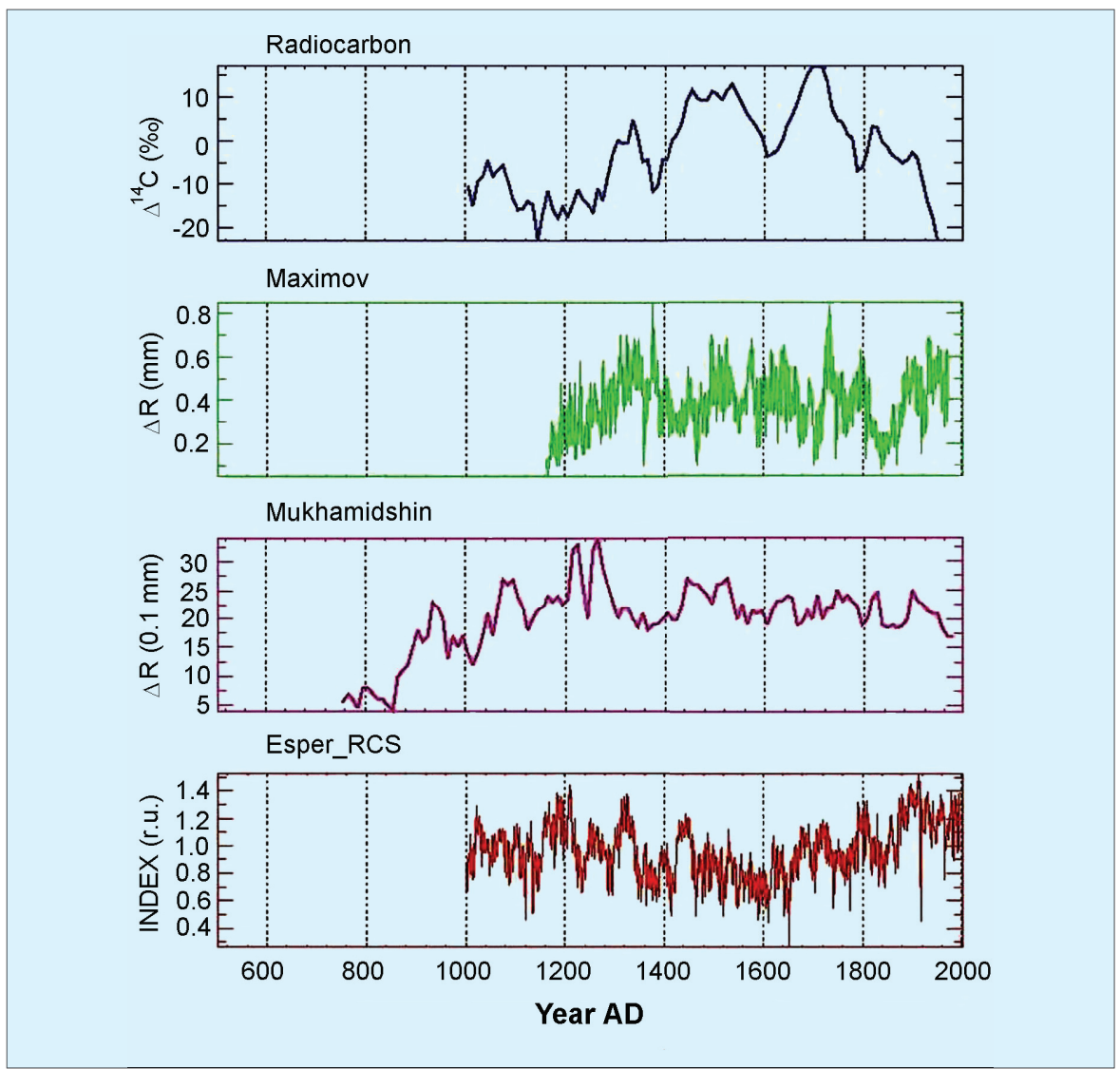

Figure 2: From top to bottom: variations in 10-year averages of $\triangle^{14} \mathrm{C}$ (Stuiver et al., 1998); tree-ring widths records ( $\triangle R$ ) by Maksimov and Grebenyuk (1972); Mukhamedshin and Sarbaev (1988) (averaged over 10-year intervals); Regional Curve Standardization (RCS) chronology (index) by Esper et al. (2003a). 
Table 1: Correlation coefficients $(R)$ and the phase shifts $\Delta t$ (years) between the records presented in Fig. 2

Corr.Coef(R) $\Delta \mathrm{t}$ (years)

\begin{tabular}{|l|c|c|}
\hline$\Delta{ }^{14} \mathrm{C}$-Maksimov & $\mathbf{0 . 8 2}$ & $\mathbf{4 0}$ \\
\hline$\Delta{ }^{14} \mathrm{C}$-Mukhamedshin & $\mathbf{0 . 5 7}$ & $\mathbf{0}$ \\
\hline$\Delta{ }^{14} \mathrm{C}$-Esper_RCS & $\mathbf{0 . 5 2}$ & $\mathbf{0}$ \\
\hline Maksimov-Mukhamedshin & $\mathbf{0 . 7 4}$ & $\mathbf{- 6 0}$ \\
\hline Maksimov - Esper_RCS & $\mathbf{0 . 7 5}$ & $\mathbf{- 2 0}$ \\
\hline
\end{tabular}

$3500 \mathrm{~m}$, about $1.5 \mathrm{~km}$ from the Matcha glacier $\left(39.5^{\circ} \mathrm{N}, 70.7^{\circ} \mathrm{E}\right)$.

- The chronology of Mukhamedshin and Sarbaev (1988) covers the interval from AD 750 to 1972. It is based on data from trees older than 650 (up to 1250) years. Samples were collected in southern Kirghizia on the northern slope of the Alay range, at elevations above $2900 \mathrm{~m}\left(39.9^{\circ} \mathrm{N}, 72.5^{\circ} \mathrm{E}\right)$. Both the Maksimov and Grebenyuk (1972), and Mukhamedshin and Sarbaev (1988) records were developed using tree discs rather than core samples.

- The third dataset used in this analysis is the Regional Curve Standardization (RCS) detrended chronology by Esper et al. (2003b), integrating Juniper core samples from several high-elevation sites (>2900 $\mathrm{m}$ asl) in the Alay range, southern Kirghizia $\left(39^{\circ} 50^{\prime}-40^{\circ} 12^{\prime} \mathrm{N}\right.$, $\left.71^{\circ} 30^{\prime}-72^{\circ} 37^{\prime} \mathrm{E}\right)$. This record spans the past millennium. All tree sites are shown in Figure 1.

To analyze long-term solar activity variations, concentrations of cosmogenic radiocarbon $\left(\Delta^{14} \mathrm{C}\right)$ derived from tree-ring data (Stuiver et al., 1998) were used. For the last millennium, the $\Delta^{14} \mathrm{C}$ data were averaged over 10-year intervals.

The $\Delta{ }^{14} \mathrm{C}$ record and the three $\Delta \mathrm{R}$ chronologies are shown in Figure 2. These data were subjected to band-pass filtering in the range of periods $180-230$ years and wavelet transformation (Morlet basis) in the range of periods 100-300 years. Band-pass filtered results are shown in Figure 3.

The band-pass filtered tree-ring chronologies of Juniperus turkestanica, that in essence represent variations in summer temperatures in Western Central Asia, and of the $\Delta^{14} \mathrm{C}$ curve all indicate pronounced $\sim 200$-year oscillations (Fig. 3). It is also evident that a decrease in the period of quasi-200-year variations during the last millennium is observed in both the $\Delta^{14} \mathrm{C}$ and dendrochronological data. The dynamic spectra of changes in solar activity and climatic processes estimated from millennium-long tree-ring records in Central Asia are similar, pointing to potential interrelations.

Figure 3 also shows that the bandpass filtered (tree ring and $\Delta^{14} \mathrm{C}$ ) records are quite synchronous. However, there is a phase shift between them (see Table).
This shift could potentially be due to the reservoir effect in $\Delta^{14} \mathrm{C}$ deposition in tree rings (Dergachev, 1977). Alternatively, local climatic conditions (proximity to glaciers, etc.) might affect the phase relation between the curves.

If we take the phase shift into account, the curves shown in Figure 3 indicate high correlation coefficients in the 180-230 year period range (see the Table). For the $\Delta^{14} \mathrm{C}$ curve and chronology of Maksimov and Grebenyuk, this

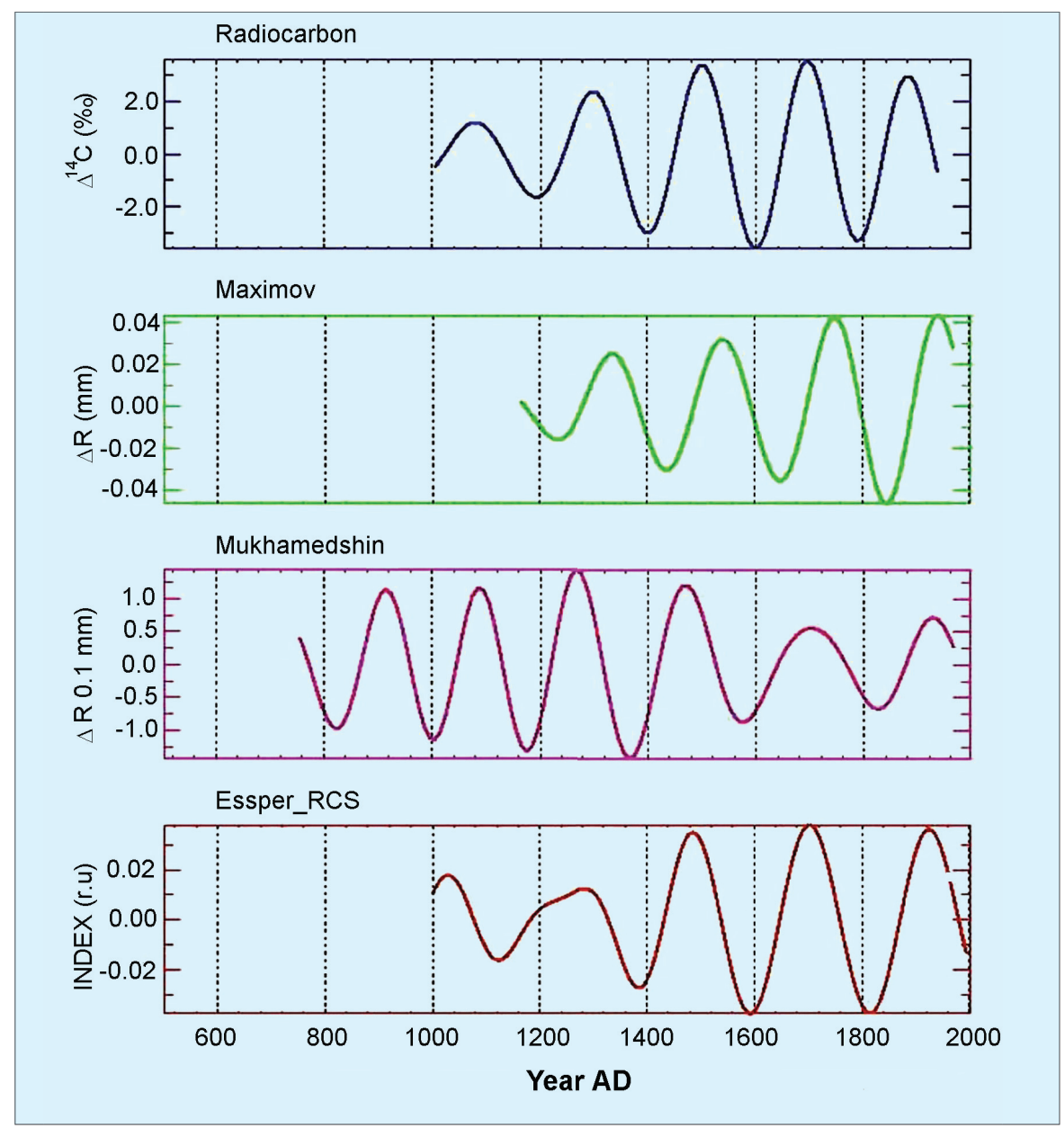

Figure 3: Results of 180-230 year band-pass filtering the data shown in Figure 2; (from top to bottom) variations in 10-year averages of $\triangle^{14} \mathrm{C}$ (Stuiver et al., 1998); variations in tree-ring width ( $\triangle R$ ) chronology of Maksimov and Grebenyuk (1972), and Mukhamedshin and Sarbaev (1988); RCS chronology (index) by Esper et al. (2003a).

coefficient reaches 0.82 . High correlation coefficients are another indicator (in addition to the dynamic spectra) suggesting interrelation between solar activity and climatic processes.

\section{Conclusions}

Our analysis of long-term dendrochronological data from Western Central Asia Juniperus turkestanica tree-ring data, developed by three independent research teams, demonstrates the presence of 200-year climatic variations over the past millennium. These variations show a high correlation (up to $\mathrm{R}=0.82$ ) with a similar periodicity (deVries period) in solar activity inferred from radiocarbon data $\left(\Delta^{14} C\right)$.

\section{Acknowledgements}

We thank Prof. Olga Solomina and Dr. Olga Kozyreva for discussion of results. This work was supported by the European Commission (Program INTAS, Projects DENDROLAB and CAMBIFORRUS), the Russian Foundation for Basic Research (projects 06-04-48792a, 06-02-16268a, 06-05-64200a), the Russian Academy of Sciences (Program N 16"Changes of Environment and (limate"), and the Swiss National Science Foundation (NCCR-Climate)

\section{References}

Esper, J., Shiyatov, S.G., Mazepa, V.S., Wilson, R.J.S., Graybill, D.A and Funkhouser, G., 2003a: Temperature-sensitive Tien Shan tree ring chronologies show multi-centennial growth trends, Climate Dynamics, 21: doi 10.1007/s00382-003-0356-y, 699.

Dergachev, V.A., 1977: A contribution to the optimal model of radiocarbon residence in the exchange reservoir. In: Proc. Intern. Conf. on Low-Level Radioactivity Measurement and Application, the High Tatras (1975), Slovensko penacladatelstvo, Bratislava. 269.

Maksimov, E.B. and Grebenyuk, A.K., 1972: Variability of natural environment of high-altitude zone of Zeravshan Range for the last 800 years, Izvestiya USSR Academy of Sciences Geographic series, 2 105 (in Russian).

Mukhamedshin, R.D. and Sarbaev, S.K., 1988: Champion of longevity, Alma-Ata, Kaynar, (in Russian).

Stuiver, M., Reimer, P.J. and Braziunas, T.F., 1998: High-precision radiocarbon age calibration for terrestrial and marine samples, Radiocarbon, $\mathbf{4 0}(3): 1127$

Vasil'ev, S.S., Dergachev, V.A. and Raspopov, 0.M., 1999: Sources of the long-term variations of the radiocarbon concentration in the Earth's atmosphere, Geomagnetism and Aeronomy, 39(6): 749. 